\title{
Large neutral amino acids block phenylalanine transport into brain tissue in patients with phenylketonuria
}

\author{
Joachim Pietz, ${ }^{1}$ Roland Kreis, ${ }^{2}$ André Rupp, ${ }^{1}$ Ertan Mayatepek, ${ }^{3}$ Dietz Rating, ${ }^{1}$ \\ Chris Boesch, ${ }^{2}$ and Hans Joachim Bremer ${ }^{2}$ \\ ${ }^{1}$ Department of Pediatric Neurology, University of Heidelberg, D-69120 Heidelberg, Germany
${ }^{2}$ Department of Magnetic Resonance Spectroscopy and Methodology, University of Berne, CH-3010 Berne, Switzerland
${ }^{3}$ Department of General Pediatrics, University of Heidelberg, D-69120 Heidelberg, Germany
}

Address correspondence to: Joachim Pietz, Department of Pediatric Neurology, University of Heidelberg, Im Neuenheimer Feld 150, D-69120 Heidelberg, Germany. Phone: 0049-6221-562311 or 0049-6221-474157; Fax: 0049-6221-565744;

E-mail: joachim_pietz@med.uni-heidelberg.de

Received for publication August 24, 1998, and accepted in revised form March 2, 1999.

\begin{abstract}
Large neutral amino acids (LNAAs), including phenylalanine (Phe), compete for transport across the blood-brain barrier (BBB) via the L-type amino acid carrier. Accordingly, elevated plasma Phe impairs brain uptake of other LNAAs in patients with phenylketonuria (PKU). Direct effects of elevated brain Phe and depleted LNAAs are probably major causes for disturbed brain development and function in PKU. Competition for the carrier might conversely be put to use to lower Phe influx when the plasma concentrations of all other LNAAs are increased. This hypothesis was tested by measuring brain Phe in patients with PKU by quantitative ${ }^{1} \mathrm{H}$ magnetic resonance spectroscopy during an oral Phe challenge with and without additional supplementation with all other LNAAs. Baseline plasma Phe was $\sim 1,000$ $\mu \mathrm{mol} / 1$ and brain Phe was $\sim 250 \mu \mathrm{mol} / 1$ in both series. Without LNAA supplementation, brain Phe increased to $\sim 400 \mu \mathrm{mol} / 1$ after the oral Phe load. Electroencephalogram (EEG) spectral analysis revealed acutely disturbed brain activity. With concurrent LNAA supplementation, Phe influx was completely blocked and there was no slowing of EEG activity. These results are relevant for further characterization of the LNAA carrier and of the pathophysiology underlying brain dysfunction in PKU and for treatment of patients with PKU, as brain function might be improved by continued LNAA supplementation.
\end{abstract}

J. Clin. Invest. 103:1169-1178 (1999).

\section{Introduction}

In phenylketonuria (PKU), an inherited disorder of amino acid (AA) metabolism (McKusick 261600), blood levels of phenylalanine (Phe) are extremely elevated because of a deficiency of phenylalanine hydroxylase (PAH; Enzyme Commission 1.14.16.1). Untreated PKU leads to disturbed brain development with profound retardation, microcephaly, epilepsy, and other neurologic symptoms, which can be widely prevented by early institution of a Phe-restricted diet. Elevated Phe levels also acutely impair brain function in early treated, and thus normally developed, patients, which was proved using neuropsychologic tasks and electroencephalogram (EEG) spectral analysis (1-3).

Because some patients are not able to adhere rigorously to the Phe-restricted diet during early years of life, and given that most patients relax or stop the diet during adolescence, alternative treatment regimens have been developed. To overcome suspected cerebral dopamine and serotonin depletion, patients with PKU who were off diet were treated with the neurotransmitter precursors tyrosine (Tyr) and tryptophan (Trp) (4). To reduce Phe influx into the brain, Berry et al. (5) supplemented the branchedchain AAs valine, isoleucine, and leucine (VIL). However, widespread acceptance could not be obtained for either of these approaches.

Despite tremendous progress in the understanding of the molecular basis of PKU, the causes of brain damage in untreated patients and of the mechanisms underlying impaired brain function occurring with acutely elevated Phe levels are still unclear. Direct effects of Phe, as well as imbalances of the large neutral amino acids (LNAAs) in brain, are thought to be major causes $(6,7)$.

In earlier studies, it was demonstrated that cerebral Phe can be readily detected noninvasively by proton magnetic resonance spectroscopy $\left({ }^{1} \mathrm{H}-\mathrm{MRS}\right)(8,9)$ and that quantitative ${ }^{1} \mathrm{H}$-MRS can be applied to reliably determine its concentrations $(9,10)$. It was also shown that the influx of Phe through the blood-brain barrier (BBB) during an oral Phe challenge can be monitored by ${ }^{1} \mathrm{H}-\mathrm{MRS}$ (11). The aim of the present study was to use this approach to further investigate Phe transport through the $\mathrm{BBB}$ in patients with PKU by manipulating blood concentrations of Phe and the LNAAs valine, methionine, isoleucine, leucine, Tyr, histidine, and Trp, while monitoring brain activity by EEG spectral analysis.

\section{Methods}

Human subjects. Six male patients with PKU were included in this study, which was approved by the Ethics Committee of the University of Heidelberg. Before the study, the experimental protocol was explained to all subjects, and their written informed consent was obtained.

The mean age of the patients was 27.6 years (range 26-30) (Table 1). None of the patients had any history of other factors disturbing brain development. Start of dietary treatment, defined by the first plasma level of Phe $<600 \mu \mathrm{mol} / \mathrm{l}$ after diet onset, was at a mean age of 38 days (range 24-63) after birth. 
Clinical phenotype was determined on the basis of Phe tolerance at five years of age (12), and standardized oral protein loading was performed mostly at the age of six years (13). Four patients (nos. 1, 2, 3, 6) still practiced a Phe-restricted diet. Long-term adult biochemical control was determined as the mean of six-month medians that were obtained from all Phe values in the last three years prior to the study.

Clinical data. Clinical evaluation (Table 1) included the identification of PAH mutations, which was based on a combination of denaturing gradient gel electrophoresis (DGGE), restriction enzyme analysis, and sequence analysis. Referring to in vitro expressions of mutations and genotype-phenotype relations, mutations were classified as either severe, moderate, or mild (12). All patients were examined with a standardized neurologic investigation, routine EEG (10/20), standard magnetic resonance imaging (MRI) examination (grading of white matter abnormalities according to Pietz et al. [14]), and intelligence testing (revised Wechsler Adult Intelligence Scale).

Ten healthy volunteers with a mean age of 25.3 years (range 20-46) were examined with ${ }^{1} \mathrm{H}-\mathrm{MRS}$ at a single point in time to determine averaged normal ${ }^{1} \mathrm{H}-\mathrm{MR}$ spectra. Their neurologic status and brain MRI scans were normal. Heterozygous status for known PAH mutations was excluded, and plasma Phe and LNAA concentrations (Table 2) were determined according to the procedures used in the patients.

Experimental protocol of Phe and LNAA intake. The study was constructed in a cross-over repeated measurement design to determine treatment effects in the six patients with PKU. Design and timing of all investigations are depicted in Figure 1. All patients were administered a single oral dose of purified L-Phe $(100 \mathrm{mg} / \mathrm{kg}$ body weight; time $0 \mathrm{~h})$ in each of two test series. In one series, termed Phe + LNAA (solid lines in all figures), Phe intake was supplemented for $12 \mathrm{~h}$ with an LNAA mixture containing $150 \mathrm{mg} / \mathrm{kg}$ body weight of each of the following AAs: valine, methionine, isoleucine, leucine, Tyr, histidine, and Trp. The LNAA mixture was divided into five equal portions and started two hours before the Phe load. The subsequent four portions were taken every three hours (one, four, seven, and 10 $h$ postload). During the experiments, the usual diet was unchanged, except that the patients still on diet did not consume their regular AA mixture. To avoid hypoglycemia due to the intake of large amounts of free AAs, regular small meals rich in free carbohydrates and poor in protein were given during both series, always about two hours before blood drawings. The results of this Phe + LNAA series were compared with an otherwise identical baseline series without LNAA intake (termed $\mathrm{Phe}_{\text {only; }}$; dotted lines in all figures). To control for effects of order, in three patients, the Phe ${ }_{+\mathrm{LNAA}}$ series was performed first; in the others, the order was reversed. The interval between the two series was four to eight weeks. Ten days after the start of each series, plasma Phe and LNAA concentrations were monitored to ensure return to pretreatment levels.

Amino acid analysis. Plasma Phe levels during the study were determined by an enzymatic assay (Quantase Phe assay; Porton, Cambridge, United Kingdom). Valine, methionine, leucine, isoleucine, Tyr, and histidine were analyzed by automated ionexchange chromatography with ninhydrin, using an AA analyzer (Sykam, Munich, Germany) following standard procedures. Plasma Trp was determined by HPLC (Beckman System Gold, Palo Alto, California, USA). To compare AA plasma levels during the LNAA supplementation and the baseline period, the area under the curve was calculated for a time range from 0.5 to $11 \mathrm{~h}$ after Phe load. During the Phe only series, plasma LNAA analysis was restricted to $-0.5,0.5$, one, five, 11 , and 24 $\mathrm{h}$ after Phe load. Blood samples for AA analysis in control subjects and for pretreatment values in the patients were taken in the morning two hours after a light standardized breakfast.

Effects of Phe loading and LNAA supplementation on carri- er-mediated Phe transport at the BBB were estimated, based on the $K_{m}$-normalized Phe ratio (ratio of Phe to the other LNAAs) regulating the influx through the $\mathrm{BBB}$ under $\mathrm{AA}$ competition for the same carrier (15):

$$
\mathrm{K}_{\mathrm{m}} \text {-normalized PHE ratio }=\frac{[\mathrm{PHE}]}{\Sigma \frac{\mathrm{K}_{\mathrm{m}}^{\text {Phe }}[\text { LNAA }]}{\mathrm{K}_{\mathrm{m}}^{[\text {LNAA }]}}}
$$

In equation $1, K$ phe and $K_{\mathrm{m}}^{\mathrm{LNAA}}$ are the absolute $K_{\mathrm{m}}$ values of Phe and all other competing LNAAs, respectively, and [PHE] and [LNAA] are their respective plasma concentrations. $K_{m}$ values (Table 2) determined in vivo in the conscious rat were used (16). Similarly $K_{m}$-normalized Tyr and Trp ratios were derived.

Proton MRS. To determine brain tissue concentrations of Phe, localized ${ }^{1} \mathrm{H}$-MRS was performed on a routine $1.5 \mathrm{~T}$ MR scanner (General Electric Medical Systems, Milwaukee, Wisconsin, USA) preload (minus one hour) and six, 12, and $24 \mathrm{~h}$ postload. Spectra from a large volume placed above the ventricular system involving white and gray matter of both hemispheres were recorded using a quadrature head coil. Voxel volume was typically $60 \times 50 \times 20 \mathrm{~mm}$. Axial $\mathrm{T}_{2}$ weighted MR images were used for accurate (re-)positioning of the MRS voxel. Four spectra of 128 acquisitions were acquired in each session, using a PRESS sequence (Bottomley, Pennsylvania, USA) with outer volume suppression, water presaturation, and phase rotation (echo time $20 \mathrm{~ms}$, repetition period three seconds, 2,048 data points) as described earlier (9). For the determination of different brain compartments and water referencing, a series of separate recordings with different echo times, but without water suppression, was acquired.

The data processing scheme used was similar to the one described in ref. 9. It is based on a three-compartment model (brain tissue, cerebrospinal fluid [CSF], blood) in which the visibility of plasma Phe was set to zero and the Phe content of CSF was assumed to be equal to that of brain tissue (rather than a steady-state relation with regard to plasma Phe, as assumed in ref. 9). Conversion to absolute concentration units was performed based on a proton signal density taken from the literature and on the unsuppressed water signal. The determination of the Phe peak area had been redesigned compared with ref. 9 . It is now performed using a versatile time-frequency domainfitting program (17) with the following steps. To parameterize normal background signals, the averaged spectrum of four normal subjects was fitted using 23 Voigt lines and a common nonanalytic line shape defined on the unsuppressed water peak (10 lines in the relevant downfield region). The spectrum of an aqueous $25 \mathrm{mM}$ Phe model solution ( $\mathrm{pH}$ 7.05) was similarly fitted and parameterized (11 Voigt lines to define the complicated strong coupling pattern). The combination of the two parameter sets (i.e., the models of Phe and the in vivo background signals each treated as nuclear magnetic resonance entities) was then used to determine the Phe peak areas in all in vivo spectra. Because the signal phase and line shapes were determined on the unsuppressed water signal, the peak area determination of the low signal-to-noise ratio peak of Phe was thus essentially reduced to amplitude fitting of background and Phe models in the real part of an absorption mode spectrum. This approach is illustrated in Figure 2 for a single spectrum $(4 \times$ 128 acquisitions) of a patient with PKU acquired before the Phe load (Figure 2a). The parameterized and line shape-adapted models of in vivo background signals and Phe are displayed in Figure 2, e and f, respectively, whereas the trace in Figure $2 \mathrm{~g}$ contains the residual spectrum, i.e., original (Figure 2a) minus best fit (Figure 2d). Spectra from model solutions of the LNAA mixture as well as Tyr and Trp were recorded to rule out confounding signal contributions of the LNAAs. 
Table 1

Genetic and clinical data of patients with PKUPatient

\begin{tabular}{|c|c|c|c|c|c|c|c|c|c|c|c|}
\hline $\begin{array}{l}\text { Patient } \\
\text { No. }\end{array}$ & $\begin{array}{l}\text { Clinical } \\
\text { PKU } \\
\text { phenotype }^{\mathrm{A}}\end{array}$ & $\begin{array}{c}\text { Mutations } \\
1 / 2\end{array}$ & $\begin{array}{c}\text { Severity } \\
\text { of } \\
\text { mutations }\end{array}$ & $\begin{array}{l}\text { PRA }^{B} \\
(\%)\end{array}$ & $\begin{array}{c}\text { Age } \\
\text { (years) }\end{array}$ & $\begin{array}{c}\text { Diet } \\
\text { onset } \\
\text { (days) }\end{array}$ & $\begin{array}{c}\text { Long-term Phe } \\
\text { last three years } \mathrm{C} \\
(\mu \mathrm{mol} / \mathrm{l})\end{array}$ & $\begin{array}{c}\text { IQ } \\
\text { WAIS-R }\end{array}$ & $\begin{array}{c}\text { Clinical } \\
\text { neurologic } \\
\text { symptoms }\end{array}$ & $\begin{array}{c}\text { EEG } \\
\text { evaluation }\end{array}$ & $\begin{array}{c}\text { MRI } \\
\text { grade }^{\mathrm{D}}\end{array}$ \\
\hline 1 & Moderate & $\begin{array}{l}\text { R261Q } \\
\text { R261Q }\end{array}$ & $\begin{array}{l}\text { Moderate } \\
\text { Moderate }\end{array}$ & $\begin{array}{l}30 \% \\
30 \%\end{array}$ & 28.2 & 46 & 899 & 106 & Tremor & Normal & 4 \\
\hline 2 & Moderate & $\begin{array}{c}\text { IVS10nt-11G }>A \\
\text { P225R }\end{array}$ & $\begin{array}{c}\text { Severe } \\
?\end{array}$ & $\begin{array}{c}\text { Null } \\
?\end{array}$ & 30.2 & 33 & 830 & 101 & - & Normal & 4 \\
\hline 3 & Moderate & $\begin{array}{l}\text { R261Q } \\
\text { G272X }\end{array}$ & $\begin{array}{l}\text { Moderate } \\
\text { Severe }\end{array}$ & $\begin{array}{l}30 \% \\
\text { Null }\end{array}$ & 26.3 & 63 & 884 & 110 & Tremor & Normal & 8 \\
\hline 4 & Moderate & $\begin{array}{l}\text { IVS12nt-1G>A } \\
\text { R261Q }\end{array}$ & $\begin{array}{c}\text { Severe } \\
\text { Moderate }\end{array}$ & $\begin{array}{l}\text { Null } \\
30 \%\end{array}$ & 26.1 & 35 & 1,357 & 61 & - & Mild & 6 \\
\hline 5 & Severe & $\begin{array}{c}\text { R408W } \\
\text { Not identified }\end{array}$ & $\begin{array}{c}\text { Severe } \\
\text { (Severe?) }\end{array}$ & $\begin{array}{c}\text { Null } \\
\text { (Null?) }\end{array}$ & 26.3 & 28 & 1,304 & 95 & - & Normal & 7 \\
\hline 6 & Moderate & $\begin{array}{l}\text { Y166X } \\
\text { R261Q }\end{array}$ & $\begin{array}{l}\text { (Severe?) } \\
\text { Moderate }\end{array}$ & $\begin{array}{c}? \\
30 \%\end{array}$ & 28.4 & 24 & 960 & 112 & - & Normal & 1 \\
\hline Mean \pm & $\pm \mathrm{SD}$ & & & & $27.6 \pm 1.6$ & $38.1 \pm 14.3$ & $1,039 \pm 230$ & $97.5 \pm 18.9$ & & & $5 \pm 2.5$ \\
\hline
\end{tabular}

APhe tolerance during the fifth year of life (15) and standardized oral protein loading studies at the age of six years were used for the determination of the clinical PKL

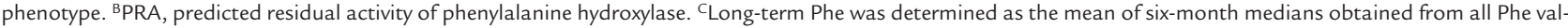
ues in the last three years prior to the study. DWAIS-R, revised Wechsler Adult Intelligence Scale. EMRI grading was performed as described in ref. 17.

Brain tissue concentrations are given in units of micromole per kilogram of wet weight. Plasma concentrations are listed in units of micromole per liter. Concentration gradients of Phe between plasma and brain are reported as dimensionless values, obtained by a unit conversion using brain and plasma density values of $1.05 \mathrm{~kg} / \mathrm{l}$.

EEG analysis. To monitor brain activity during the two series in the six patients with PKU, EEGs in the relaxed awake state with eyes closed were derived $-2.5 \mathrm{~h}$ preload (before first LNAA intake) and $-0.5 \mathrm{~h}$ preload (after first LNAA intake), as well as $5.5,11.5$, and $23.5 \mathrm{~h}$ postload immediately before the ${ }^{1} \mathrm{H}$-MRS session. To control for diurnal variations of EEG spectra, $\mathrm{Phe}_{+\mathrm{LNAA}}$ and $\mathrm{Ph} \mathrm{e}_{\text {only }}$ series were parallel with respect to the time of Phe loading and subsequent EEG investigations, thereby ensuring that diurnal variations of EEG activity were taken into account. Electrode locations were according to the $10 / 20$ system (monopolar, common reference, $\mathrm{F}=128 \mathrm{~Hz}$, time constant $=1.0)$. EEG activity was digitized with $256 \mathrm{~Hz}$ and stored on a personal computer. From each single recording of about 10 min duration, 16-20 artifact-free sections of $4.096 \mathrm{~s}$ were chosen visually. Spectral analysis was performed by fast Fourier transformation. Relative power (calculated as percentage of total power within the $1.5-25 \mathrm{~Hz}$ range) was computed for the $\delta(1.5-3.5 \mathrm{~Hz}), \theta(3.5-7.5 \mathrm{~Hz}), \alpha 1(7.5-9.5 \mathrm{~Hz}), \alpha 2(9.5-12.5 \mathrm{~Hz})$, $\beta 1(12.5-18.5 \mathrm{~Hz})$, and $\beta 2(18.5-25 \mathrm{~Hz})$ bands from averaged spectra. In addition, the mean frequency of the power spectrum from 1.5 to $25 \mathrm{~Hz}$ (mean power frequency [MPF]), the frequency of maximum power within the $\alpha$ band (peak frequency $[\mathrm{PF}]$ ), and the proportion of the power in the $\alpha$ band to the power in the $\theta$ band ( $\alpha / \theta$ ratio), were derived from power spectra. Statistical evaluation was restricted to lead $\mathrm{O}_{\mathrm{z}}$. Comparable results were determined at other locations. All EEGs were also assessed by standard visual criteria.

Statistical analysis. Statistics were computed by SAS, version 6.12 (SAS Inc., Cary, North Carolina, USA). Comparison of means within, as well as between, the two series $\left(\mathrm{Phe}_{+\mathrm{LNAA}}, \mathrm{Phe}_{\text {on- }}\right.$ ly) were compared by Student's paired $t$ tests. Because of the small number of observations, correlational analysis was done by calculation of rank correlational coefficients (Kendall's $\tau_{\mathrm{b}}$ ).

\section{Results}

Clinical data. On the basis of clinical data (Table 1), five patients corresponded to moderate PKU, and one patient had a severe type. Mutations were mostly typical for European patients with PKU, e.g., R408W, R261Q,
G272X. In P225R, first described in a Sweden, and in Y166X, which was not described earlier, the severity of the mutations are unknown. In patient no. 5, one mutation could not be determined, despite repeated DGGE analysis. Assuming a large deletion or mutation in one of the large introns, a null mutation (residual activity $<1 \%)$ is most probable. Regarding Phe tolerance at five years (12) and data from standardized protein loading tests (13), clinical phenotype and genotype corresponded. Neurologic status was normal except for mild tremor, which was present in two patients. Long-term baseline Phe values during adult age were lower in patients on diet compared with patients off diet.

Baseline measurements. Plasma Phe was normal in all control subjects (mean $66 \pm 9 \mu \mathrm{mol} / \mathrm{l}$ ). In the six patients with PKU, preload plasma Phe values (Table 2) ranged between 796 and $1,459 \mu \mathrm{mol} / 1$ and were thus in the typical longterm range of these patients. Mean preload plasma Phe concentrations before start of the Phe load and LNAA treatment did not differ between both series $(t=0.76$, not significant [ns]). Mean pretreatment plasma concentrations of all other LNAAs (Phe + LNAA -10 and $-2.5 \mathrm{~h}$; Phe $_{\text {on- }}$ ly $-0.5 \mathrm{~h}$ ) were also comparable for the two series (Table 2 and Figure 3). Before the Phe load, mean $K_{\mathrm{m}}$-normalized Phe ratios of 5.7 and 5.6 resulted for the Phe only and the Phe + LNAA series, respectively (Table 3 ), in comparison with a mean $K_{\mathrm{m}}$-normalized Phe ratio of $0.33 \pm 0.04$ in the control subjects. Preload $K_{\mathrm{m}}$-normalized Tyr and Trp ratios for the PKU patients were 0.015 and 0.026 , respectively, in both series (Table 3), compared with 0.09 (Tyr ratio) and 0.19 (Trp ratio) in the control subjects.

In all 12 preload ${ }^{1} \mathrm{H}-\mathrm{MR}$ spectra of the patients, excess Phe peaks at $7.37 \mathrm{ppm}$ were identified; these peaks are attributed to the phenyl protons of Phe. Figure 2 contains the spectrum for one patient before the Phe load in the Phe only $_{\text {s }}$ series (plasma Phe of $1,193 \mu \mathrm{M}$; brain Phe 265 $\mu \mathrm{mol} / \mathrm{kg}$ ) and demonstrates the signal-to-noise ratio achieved for single data points. Absolute brain tissue concentrations of Phe are listed in Table 3. Mean statistical uncertainty of a single brain Phe measurement (mean SEM of four spectra for each session) was 17 and 19 $\mu \mathrm{mol} / \mathrm{kg}$ for the Phe only $_{\text {and }}$ Phe + LNAA series, respectively, 


\section{Figure 1}

Study design. In the Phe only series (left), plasma concentrations of Phe and the other LNAAs were determined during an oral Phe load. Brain tissue concentrations of Phe were measured with in vivo ${ }^{1} \mathrm{H}-\mathrm{MRS}$. Brain activity was monitored using spectral analysis of EEG activity. In the Phe + LNAA series (right), this experiment was supplemented by LNAA treatment with $5 \times 30 \mathrm{mg} / \mathrm{kg}$ body weight.

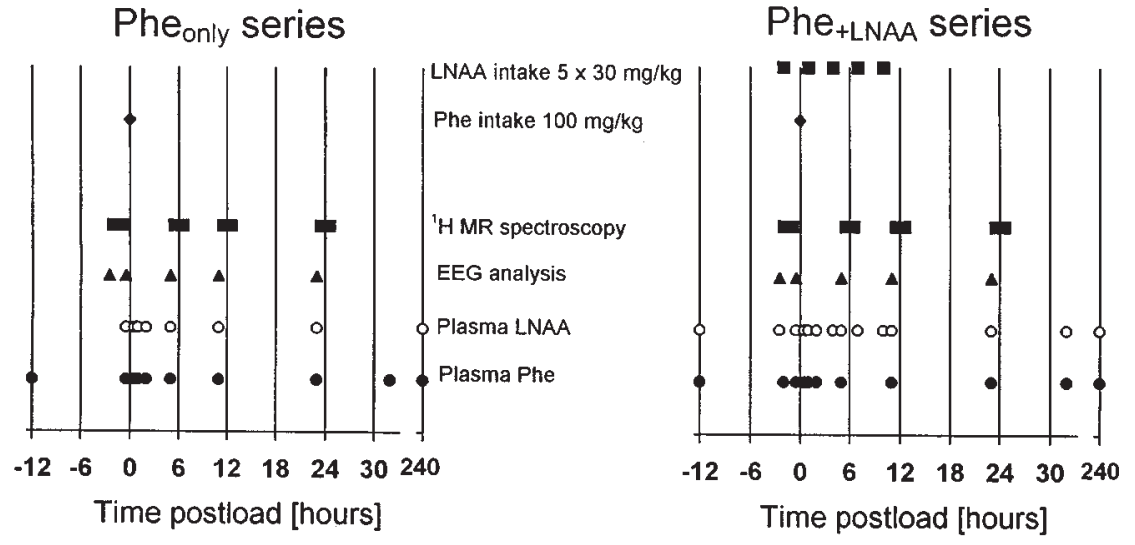

i.e. $~ 7 \%$ of the measured values. Preload brain Phe concentrations were not significantly different $(t=1.4$, ns) for the two series. However, the mean plasma/brain ratio was somewhat lower during the Phe only $_{\text {series }}(t=2.05, P<$ $0.10)$. Preload plasma and brain Phe concentrations correlated significantly during the Phe only $_{\text {series }}\left(\tau_{\mathrm{b}}=0.87, P\right.$ $<0.05)$ but not during the Phe + $_{\text {LNAA }}$ series $\left(\tau_{\mathrm{b}}=0.33\right.$, ns $)$.

Dynamic data during Phe and LNAA intake. After the oral Phe load, plasma Phe values (Figure 3a) steeply increased to reach a maximum one hour postload during both series and slowly decreased thereafter. In the Phe only $_{\text {. }}$ series, plasma Phe increase in comparison with preload values was $82 \%(854 \pm 101 \mu \mathrm{mol} / \mathrm{l})$ six hours postload, $78 \%(802 \pm 133 \mu \mathrm{mol} / \mathrm{l}) 12 \mathrm{~h}$ postload, and 63\% (657 \pm $123 \mu \mathrm{mol} / \mathrm{l}) 24 \mathrm{~h}$ postload. In the Phe ${ }_{+\mathrm{LNAA}}$ series, plasma Phe increase was $75 \%(797 \pm 368 \mu \mathrm{mol} / \mathrm{l})$ six hours postload, $55 \%(579 \pm 238 \mu \mathrm{mol} / \mathrm{l}) 12 \mathrm{~h}$ postload, and $38 \%$ $(405 \pm 212 \mu \mathrm{mol} / \mathrm{l}) 24 \mathrm{~h}$ postload. Comparing plasma Phe concentrations in the two series, these were similar six hours postload $(t=0.02, \mathrm{~ns})$. In the Phe ${ }_{+ \text {LNAA }}$ series, plasma Phe was $9 \%$ lower $12 \mathrm{~h}$ postload $(t=2.5, P<0.10)$ and $12 \%$ lower $24 \mathrm{~h}$ postload $(t=3.6, P<0.05)$ in comparison with the Phe only $_{\text {s }}$ series. Phe levels had decreased by $17 \%\left(\right.$ Phe $\left._{\text {only }}\right)$ and $20 \%$ (Phe + LNAA $)$, respectively, at $24 \mathrm{~h}$ compared with maximum Phe at one hour postload. Ten days later, Phe levels had returned to preload values in both series and in all patients.

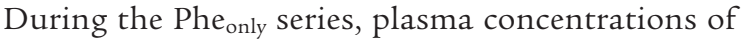
some other LNAAs decreased slightly in the postload period (Table 2). This was statistically significant for isoleucine $(t=3.8, P<0.05)$ and $\operatorname{Trp}(t=6.7, P<0.01)$. During the Phe +LNAA $_{\text {series, LNAA supplementation }}$ started at minus two hours and led to a substantial increase in plasma LNAA concentrations in all seven AAs (Table 2). The courses of valine (Figure 3b), methionine, isoleucine, and leucine plasma concentrations from preload to $12 \mathrm{~h}$ postload showed a marked jitter, attributed to both fast absorption from the gastrointestinal tract and fast elimination from blood, whereas the courses of Tyr, histidine, and Trp (Figure 3c) concentrations were found to be smoother. During LNAA treatment, lysine concentrations decreased by $\sim 30 \%$. As lysine levels also slightly decreased in the Phe $\mathrm{P}_{\text {only }}$ series compared with pretreatment levels (Table 2), there was no significant difference between the series $(t=1.9, P=$ $0.11)$. However, an effect of LNAA treatment on plasma lysine levels has to be assumed. Also, other AAs showed a slight decrease of plasma concentrations postload. This effect was present in both series, e.g., ornithine Phe only $_{\text {series: }}-14 \mu \mathrm{mol} / 1$, approximately $-18 \%$; Phe + LNAA series: $-10 \mu \mathrm{mol} / 1$, approximately $-12 \%$, compared with pretreatment levels. Most LNAA concentrations and

Table 2

Plasma LNAA concentrations in patients with PKU

\begin{tabular}{|c|c|c|c|c|c|c|c|}
\hline \multirow[b]{2}{*}{ LNAAs } & \multicolumn{7}{|c|}{$\begin{array}{c}\text { Phe } \text { only series (baseline) }_{100 \mathrm{mg} / \mathrm{kg}}\end{array}$} \\
\hline & $\begin{array}{c}K_{m} \\
\text { values } \\
(\mu \mathrm{mol})^{\mathrm{A}}\end{array}$ & $\begin{array}{c}\text { Control }^{\mathrm{B}} \\
n=10 \\
(\mu \mathrm{mol} / \mathrm{I})\end{array}$ & $\begin{array}{c}\text { Pretreatment } \\
\text { Phe }-0.5 \text { h } \\
\text { LNAA }-0.5\end{array}$ & $\begin{array}{l}\text { Postload } \\
\text { six hours }{ }^{C}\end{array}$ & $\begin{array}{c}\text { Postload } \\
12 \mathrm{~h}^{\mathrm{C}}\end{array}$ & $\begin{array}{l}\text { Treatment } \\
\text { Mean } \\
0.5-11 \mathrm{~h}^{\mathrm{C}}\end{array}$ & $\begin{array}{c}\text { Postload } \\
24 \mathrm{~h}^{\mathrm{C}}\end{array}$ \\
\hline Phenylalanine & $32 \pm 9$ & $66 \pm 9$ & $1,036 \pm 199$ & $1,890 \pm 244 * * *$ & $1,838 \pm 181 * * *$ & $1,893 \pm 203 * * *$ & $1,693 \pm 196 * * *$ \\
\hline Valine & $168 \pm 72$ & $211 \pm 33$ & $218 \pm 59$ & $204 \pm 48$ & $237 \pm 21$ & $198 \pm 34$ & $215 \pm 55$ \\
\hline Isoleucine & $145 \pm 29$ & $67 \pm 12$ & $71 \pm 14$ & $54 \pm 17^{*}$ & $68 \pm 135$ & $53 \pm 14^{*}$ & $57 \pm 18^{* *}$ \\
\hline Leucine & $87 \pm 11$ & $128 \pm 22$ & $136 \pm 21$ & $120 \pm 42$ & $135 \pm 32$ & $115 \pm 37$ & $109 \pm 36^{*}$ \\
\hline Tyrosine & $86 \pm 17$ & $59 \pm 11$ & $43 \pm 7$ & $40 \pm 11$ & $54 \pm 13$ & $39 \pm 9$ & $47 \pm 13$ \\
\hline Histidine & $164 \pm 28$ & $82 \pm 9$ & $85 \pm 14$ & $74 \pm 15$ & $82 \pm 8$ & $73 \pm 12$ & $78 \pm 10$ \\
\hline Tryptophan & $52 \pm 14$ & $68 \pm 13$ & $49 \pm 10$ & $34 \pm 9 * *$ & $41 \pm 9 *$ & $35 \pm 8^{* *}$ & $34 \pm 6^{* *}$ \\
\hline Lysine & - & $178 \pm 33$ & $161 \pm 33$ & $150 \pm 48$ & $170 \pm 63$ & $146 \pm 41$ & $155 \pm 49$ \\
\hline
\end{tabular}

${ }^{A} K_{m}$ values of AA transport at the blood-brain barrier determined in the conscious rat, according to ref. 19; the $K_{m}$ of lysine, which does not belong to the group of LNAAs, was not determined. ${ }^{B}$ Normal data were obtained from 10 healthy subjects who also served in the determination of normal reference ${ }^{1} \mathrm{H}$-MR spectra. ${ }^{\mathrm{C} S i g n i f i c a n c e}$ values are given for differences 
lysine were back in the pretreatment range $14 \mathrm{~h}$ after stopping LNAA supplementation, i.e., $24 \mathrm{~h}$ after the Phe load. However, mean concentrations for methionine $(+196 \%)$, Tyr $(+43 \%)$, and histidine $(+20 \%)$ were still above pretreatment levels. Ten days after the Phe load, all LNAA levels were in the pretreatment range.

The $K_{m}$-corrected Phe/LNAA ratio (Table 3 and Figure $3 d)$ more than doubled in the Phe only series, whereas it decreased under LNAA treatment, i.e., up to $12 \mathrm{~h}$. In the Phe only series, $K_{m}$-normalized $\mathrm{Tyr}$ and $\operatorname{Trp}$ ratios decreased. However, in the Phe + LNAA series, they increased despite elevation of plasma Phe.

In vivo ${ }^{1} \mathrm{H}$-MRS (Figures $3 \mathrm{e}$ and 4 ) revealed totally different courses of cerebral Phe levels with and without LNAA supplementation. The data from the Phe only $_{\text {series }}$ confirmed that an increase in plasma Phe leads to a significant, but delayed, increase of Phe concentrations in brain tissue (preload to six hours postload; $t=6.4, P<$ $0.01)$. On average, this increase still continued after $12 \mathrm{~h}$, and brain Phe levels were higher at $24 \mathrm{~h}$ compared with $12 \mathrm{~h}$ postload (Table 3 ). Total increase from preload to $24 \mathrm{~h}$ postload was $64 \%$. During the Phe + LNAA series, the influx of Phe into brain tissue was totally blocked for 12 $\mathrm{h}$ (Figure $3 \mathrm{e}$ ). From preload to $12 \mathrm{~h}$ postload, brain Phe even decreased by $5 \%$, although this difference was not significant $(t=-1.2$, ns). After stopping LNAA supplementation, brain Phe also increased during the Phe + LNAA series. Total increase from preload to $24 \mathrm{~h}$ postload was $41 \%$ in the Phe + LNAA ${ }_{\text {L }}$ series $(t=3.8, P<0.05)$. The effects of Phe loading during the two series are also viewed in Figure 4 . The differing sizes of the Phe peaks from difference spectra (PKU minus control) reflect the differing cerebral Phe levels. Because of a delayed influx from plasma into brain tissue, plasma/brain ratios of Phe (Figure

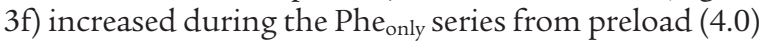
to six hours (5.3) and $12 \mathrm{~h}$ (4.7) postload. This ratio returned to preload values $24 \mathrm{~h}$ postload (4.2). As plasma Phe concentrations increased, and brain Phe remained stable, the increase of the plasma/brain ratio six hours and $12 \mathrm{~h}$ postload was much more pronounced during the Phe + LNAA series.

The ${ }^{1} \mathrm{H}-\mathrm{MR}$ spectra did not show contributions from any of the supplemented LNAAs. In particular, there was no indication for a doublet at $1 \mathrm{ppm}$ that would be characteristic for valine, which reached almost $1 \mathrm{mM}$ in plasma.

Monitoring brain activity by EEG spectral analysis. The effect of Phe intake on EEG activity (Table 3 and Figure 5) was also different for the two series. Although the individual profiles of the power spectra were reproduced in all EEG derivations of both series, a shift of the dominant peak of background activity to the lower-frequency spectrum was observed for the Phe only $_{\text {s }}$ series from six hours postload onward. This dominant peak was located in the center of the $\alpha$ band in five patients. Figure 5 contains the averaged EEG power spectra of all six patients from $-2.5 \mathrm{~h}$ preload to $24 \mathrm{~h}$ postload. Calculation of the relative power in conventional frequency bands confirmed Phe-related changes in EEG spectra. A significant increase of $\theta$ activity from preload to $24 \mathrm{~h}$ postload $(t=3.6, P<0.05)$ was accompanied by a simultaneous decrease of $\alpha 2$ activity $(t=-3.5, P$ $<0.05)$. Consequently, the $\alpha / \theta$ ratio decreased continuously from preload to $24 \mathrm{~h}$ postload in the $\mathrm{Phe}_{\text {only }}$ series. Similarly, PF $(t=-6.0, P<0.01)$ and $\operatorname{MPF}(t=-4.9, P<0.01)$ decreased by $0.4 \mathrm{~Hz}$ (Table 3$)$. These changes were noted in all six patients; $\delta, \alpha 1$, and $\beta$ activity were unchanged.

During the Phe + LNAA series, comparable effects were not observed (Figure 5). EEG power spectra from $-2.5 \mathrm{~h}$ preload (before first LNAA intake) and $-0.5 \mathrm{~h}$ preload (after first LNAA intake) were comparable. An increase in fast $\alpha$ activity, as well as PF and MPF, was observed in EEGs $12 \mathrm{~h}$ postload, i.e., around midnight. The following morning, which was $24 \mathrm{~h}$ after Phe intake, EEG activity was not significantly different compared with preload measurements. Comparing Phe only $_{\text {and Phe }}$ +LNAA series, differences were statistically significant for $\theta$ activity 24 h postload, $\alpha 2$ activity 12 and $24 \mathrm{~h}$ postload, as well as the $\alpha / \theta$ ratio 12 and 24 h postload (Table 3 ).

Visual evaluations of all EEG recordings from both series revealed no abnormalities. In particular, abnormal EEG patterns, like epileptiform activity, were not observed. During both Phe only $_{\text {and Phe }}$ +LNAA series, no side effects were registered, except for feelings of satiation after LNAA intake. Blood glucose levels were above $4.4 \mathrm{mmol} / 1$ at regular checks. Standard laboratory evaluations (red and white blood cell counts, electrolytes, transaminases) remained in the normal range.
Table 2

(Continued)

\begin{tabular}{|c|c|c|c|c|c|}
\hline \multirow[b]{2}{*}{ LNAAs } & \multicolumn{4}{|c|}{$\begin{array}{l}\text { Phe }+ \text { LNAA series } \\
\text { Phe at time } 0 \mathrm{~h}\end{array}$} & \multirow[b]{2}{*}{$\begin{array}{c}\text { Postload } \\
24 \mathrm{~h}^{\mathrm{C}}\end{array}$} \\
\hline & $\begin{array}{c}\text { Pretreatment } \\
\text { Phe }-0.5 \\
\text { LNAA }-2.5 \mathrm{~h}\end{array}$ & $\begin{array}{l}\text { Postload } \\
\text { six hours }{ }^{C}\end{array}$ & $\begin{array}{c}\text { Postload } \\
12 \mathrm{~h}^{\mathrm{C}}\end{array}$ & $\begin{array}{l}\text { Treatment } \\
\text { Mean } \\
0.5-11 \mathrm{~h}\end{array}$ & \\
\hline Phenylalanine & $1,063 \pm 189$ & $1,887 \pm 235^{* *}$ & $1,669 \pm 168^{* *}$ & $1,755 \pm 80^{* * *}$ & $1,495 \pm 128^{* *}$ \\
\hline Valine & $258 \pm 72$ & $837 \pm 250 * * *$ & $816 \pm 191 * * *$ & $622 \pm 117^{* * *}$ & $311 \pm 72 *$ \\
\hline Methionine & $40 \pm 8$ & $404 \pm 178^{* *}$ & $551 \pm 192^{* * *}$ & $334 \pm 108^{* * *}$ & $123 \pm 80^{*}$ \\
\hline Isoleucine & $82 \pm 11$ & $377 \pm 118 * * *$ & $332 \pm 109 * *$ & $218 \pm 46^{* * *}$ & $69 \pm 22$ \\
\hline Leucine & $146 \pm 45$ & $398 \pm 105^{* * *}$ & $338 \pm 88^{* *}$ & $243 \pm 42 * *$ & $115 \pm 32$ \\
\hline Tyrosine & $53 \pm 22$ & $198 \pm 65 * * *$ & $202 \pm 64 * * *$ & $181 \pm 41 * * *$ & $68 \pm 14^{*}$ \\
\hline Histidine & $88 \pm 13$ & $224 \pm 71 * *$ & $226 \pm 64^{* *}$ & $174 \pm 38^{* *}$ & $104 \pm 19 *$ \\
\hline Tryptophan & $54 \pm 16$ & $234 \pm 38 * * *$ & $212 \pm 67^{* *}$ & $206 \pm 31 * * *$ & $54 \pm 16$ \\
\hline Lysine & $149 \pm 24$ & $103 \pm 32 *$ & $105 \pm 53$ & $101 \pm 34^{*}$ & $129 \pm 16$ \\
\hline
\end{tabular}

between preload and postload values within the two series: ${ }^{*} P<0.05,{ }^{* *} P<0.01,{ }^{*}{ }^{*} P<0.001$. Because of repeated use of the preload data, significance with $P<0.05$ should be treated with caution.

\section{Discussion}

In this study, brain Phe concentrations were measured by means of in vivo ${ }^{1} \mathrm{H}-\mathrm{MRS}$ in two series of AA loading experiments in patients with PKU. Our results prove that despite significantly increasing plasma Phe values, cerebral Phe concentrations remained unchanged, or were even lowered, during concomitant high-dose oral intake of an LNAA mixture. Although a complete block of Phe influx seems to be the most plausible explanation, other mechanisms (e.g., influences on cerebral Phe metabolism as well as AA efflux from brain) have to be considered. It was shown that high brain Phe concentrations cause a slowing of electrical brain activity and that this effect can be avoided by LNAA supplementation. These main results are relevant to basic research 
Figure 2

Downfield portion of the ${ }^{1} \mathrm{H}-\mathrm{MR}$ spectrum. (a) Spectrum of a 26-year-old patient with PKU. (b) The averaged spectrum of 10 healthy age-matched subjects, and (c) the corresponding spectrum of an aqueous solution of Phe. The right side illustrates the model-fitting procedure used. Spectrum (d) contains the bestfitting model for spectrum a, which is composed of a parameterized spectrum of normal background and residual water signals (e) as well as the parameterized spectrum of Phe (f). Trace (g) contains the residuals of the best fit (i.e., a-d) for this case.

addressing the properties of the LNAA carrier through the $\mathrm{BBB}$ and to understanding the biochemical mechanisms underlying brain dysfunction in PKU. They are also significant for treatment of patients with PKU.

LNAA carrier system. Normal brain development and function depend on the continuous influx of nutrients through the BBB. Therefore, the properties of specific transport systems have been an essential issue in the understanding of physiological as well as pathophysiological conditions. For LNAAs, net uptake through the BBB is determined by their ratio in plasma and their different affinity to the stereospecific L-type AA carrier system (18-21). Carrier saturation and competitive inhibition of the influx of other LNAAs can be expected at supraphysiological plasma Phe levels usually found in PKU and may be present already at concentrations in the range of $200-500 \mu \mathrm{mol} / 1$ (18). The $K_{\mathrm{m}^{-}}$ normalized Phe/LNAA ratio was calculated using measured plasma concentrations and $K_{m}$ values from the literature. It predicted that in the $\mathrm{Phe}_{\text {only }}$ series, the increase of plasma Phe should lead to a further increase in brain Phe uptake, whereas in the Phe + LNAA series, brain Phe uptake should decrease despite doubled plasma Phe. The ${ }^{1} \mathrm{H}-\mathrm{MRS}$ and EEG measurements presented prove these predictions to be correct and the underlying model valid.

The applicability of such a simple model to the in vivo situation is surprising because the calculation of LNAA transport on the basis of apparent $K_{m}$ values under non-steady state conditions obviously disregards some
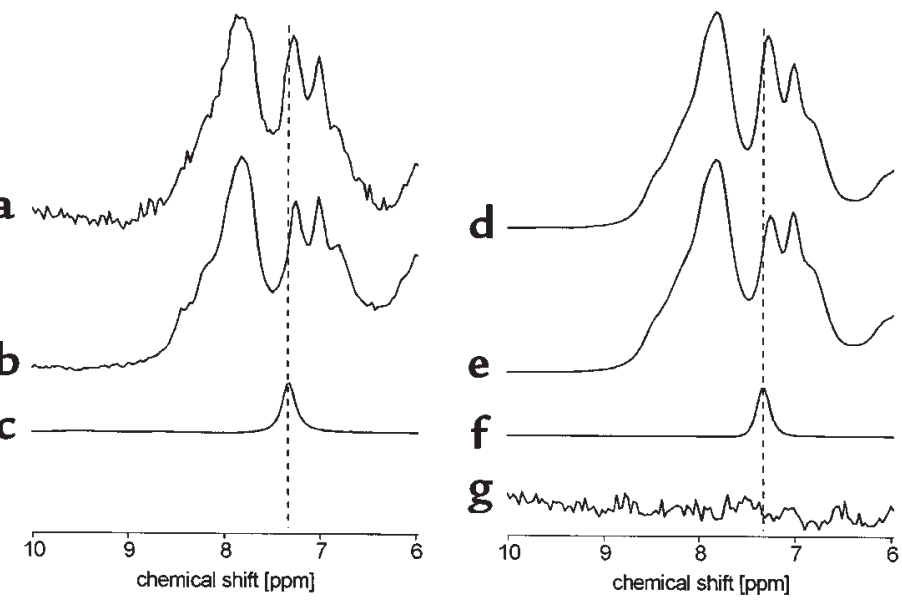

important aspects. First, it may appear questionable to use $K_{m}$ values obtained in an animal study, but there exists agreement in the literature that $K_{m}$ values can be transferred from animals to humans $(16,18,19,21)$. Second, $K_{m}$ values reported in the literature vary to some degree, even within one species, depending on the experimental approaches used. However, the main results from using the equation for competing enzyme kinetics are well reproduced, even when other sets of $K_{m}$ values are used $(19,20)$. Only the use of $K_{m}$ values determined in vitro in isolated human capillaries (21) produced somewhat different results, with smaller effects of LNAA competition. This confirms that results from in vitro studies cannot directly be transferred to the in vivo situation. Third, AA uptake by the brain cannot be fully described by a simple two-compartment model. AA transport also occurs at cellular and intracellular membranes (22). Thus, the distribution of AAs into different compartments and fluid spaces, as well as efflux from brain, ought to be considered $(23,24)$. Furthermore, glia and neuronal cells seem to be different with regard to their free AA pools (24). However, it appears that LNAA uptake via the high-affinity L-type carrier at the endothelial wall constitutes the rate-limiting step under physio-

Table 3

Plasma and brain Phe concentrations, $K_{m}$-normalized Phe/LNAA ratio, plasma/brain Phe ratio, and EEG spectral parameters in PKU patients as functions of time

\begin{tabular}{|c|c|c|c|c|c|c|c|c|}
\hline & \multicolumn{4}{|c|}{ Phe $_{\text {only }}$ series (baseline) } & \multicolumn{4}{|c|}{ Phe $_{+ \text {LNAA }}$ series $100 \mathrm{mg} / \mathrm{kg}$ Phe at time $0 \mathrm{~h}$} \\
\hline & Preload & $\begin{array}{l}\text { Postload } \\
\text { six hours }\end{array}$ & $\begin{array}{c}\text { Postload } \\
12 \mathrm{~h}\end{array}$ & $\begin{array}{c}\text { Postload } \\
24 \mathrm{~h}\end{array}$ & Preload & $\begin{array}{l}\text { Postload } \\
\text { six hours }\end{array}$ & $\begin{array}{c}\text { Postload } \\
12 \mathrm{~h}\end{array}$ & $\begin{array}{c}\text { Postload } \\
24 \mathrm{~h}\end{array}$ \\
\hline Plasma Phe $(\mu \mathrm{mol} / \mathrm{I})^{\mathrm{A}}$ & $1,036 \pm 199$ & $1,890 \pm 244^{* * *}$ & $1,838 \pm 181^{* * *}$ & $1,693 \pm 196^{* * *}$ & $1,063 \pm 189$ & $1,887 \pm 235^{* *}$ & $1,669 \pm 168^{* *}$ & $1,495 \pm 128^{* *}$ \\
\hline$K_{m}$-normalized Phe ratio ${ }^{A}$ & $5.7 \pm 1.4$ & $12.0 \pm 1.7^{* *}$ & $10.3 \pm 2.2^{* *}$ & $11.1 \pm 2.4^{* *}$ & $5.6 \pm 2.0$ & $2.4 \pm 0.4^{* *}$ & $2.1 \pm 0.4^{* *}$ & $6.4 \pm 1.5$ \\
\hline$K_{m}$-normalized Tyr ratio ${ }^{A}$ & $0.015 \pm 0.003$ & $0.007 \pm 0.002^{*}$ & $0.01 \pm 0.003$ & $0.01 \pm 0.003$ & $0.015 \pm 0.007$ & $0.028 \pm 0.007^{* * *}$ & $0.032 \pm 0.007^{* *}$ & $0.015 \pm 0.004$ \\
\hline$K_{m}$-normalized Trp ratio ${ }^{A}$ & $0.026 \pm 0.006$ & $0.011 \pm 0.003^{* * *}$ & $0.013 \pm 0.003^{* * *}$ & $0.012 \pm 0.002^{* * *}$ & $0.026 \pm 0.009$ & $0.057 \pm 0.009^{* *}$ & $0.055 \pm 0.011^{* *}$ & $0.019 \pm 0.005$ \\
\hline Brain Phe $(\mu \mathrm{mol} / \mathrm{kg} \text { wet weight })^{A}$ & $252 \pm 73$ & $344 \pm 54^{* *}$ & $377 \pm 80^{* * *}$ & $397 \pm 88^{* *}$ & $226 \pm 52$ & $235 \pm 33$ & $210 \pm 31$ & $309 \pm 45^{*}$ \\
\hline Plasma/brain ratio Phe $e^{A, B}$ & $4.0 \pm 0.4$ & $5.3 \pm 0.6^{* *}$ & $4.7 \pm 0.6^{* *}$ & $4.2 \pm 0.6$ & $4.6 \pm 0.9$ & $7.9 \pm 2.0^{* *}$ & $7.7 \pm 1.4^{* *}$ & $4.7 \pm 0.7$ \\
\hline EEG: $\theta$ band $(\%)^{c}$ & $19.6 \pm 11.5$ & $24.1 \pm 14.7$ & $23.5 \pm 14.8$ & $24.8 \pm 13.8$ & $16.1 \pm 5.5$ & $15.5 \pm 6.3$ & $13.4 \pm 4.1 \neq$ & $19.3 \pm 10.7^{* *}$ \\
\hline EEG: $\alpha 2$ band $(\%)^{c}$ & $16.2 \pm 10.2$ & $13.2 \pm 9.4$ & $14.2 \pm 9.1$ & $11.3 \pm 9.1$ & $16.5 \pm 9.8$ & $16.9 \pm 7.7$ & $26.8 \pm 13.0^{*}$ & $16.7 \pm 10.7^{* *}$ \\
\hline EEG: $\alpha / \theta$ ratio ${ }^{c}$ & $4.5 \pm 4.2$ & $3.8 \pm 3.0$ & $3.5 \pm 2.7$ & $3.0 \pm 2.1$ & $4.5 \pm 1.8$ & $4.9 \pm 2.4$ & $5.6 \pm 2.5^{* *}$ & $4.1 \pm 2.4^{* *}$ \\
\hline EEG: $P F(H z)^{C}$ & $9.7 \pm 0.5$ & $9.3 \pm 0.6$ & $9.5 \pm 0.9$ & $9.2 \pm 0.5$ & $9.7 \pm 0.5$ & $9.7 \pm 0.3$ & $10.1 \pm 0.7^{\ddagger}$ & $9.3 \pm 0.7$ \\
\hline EEG: MPF (Hz) & $9.3 \pm 0.6$ & $9.1 \pm 0.9$ & $9.3 \pm 1.1$ & $8.8 \pm 0.8$ & $9.5 \pm 0.3$ & $9.4 \pm 0.3$ & $9.8 \pm 0.3$ & $9.2 \pm 0.5$ \\
\hline
\end{tabular}

ASignificance values are given for differences between preload and postload values within the two series: ${ }^{*} P<0.05,{ }^{*} P<0.01$, ${ }^{* * *} P<0.001$. Because of repeated use of the preload data, significance with $P<0.05$ should be treated with caution. BFor the calculation of ratios, brain tissue concentrations were transformed to $\mu$ mol/I

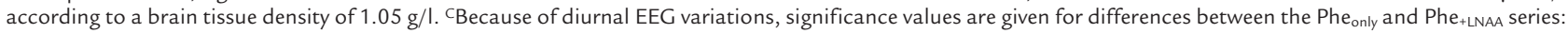
$\neq P<0.10, *{ }^{*} P<0.05, * * P<0.01$ 


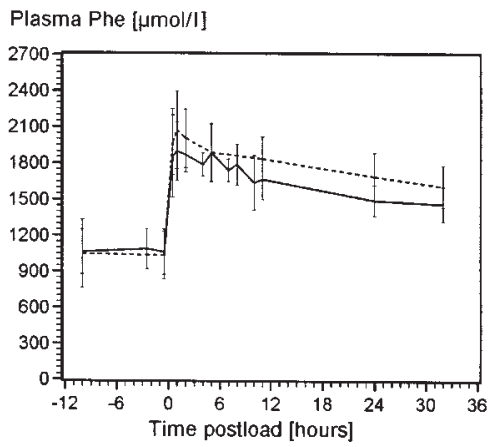

d

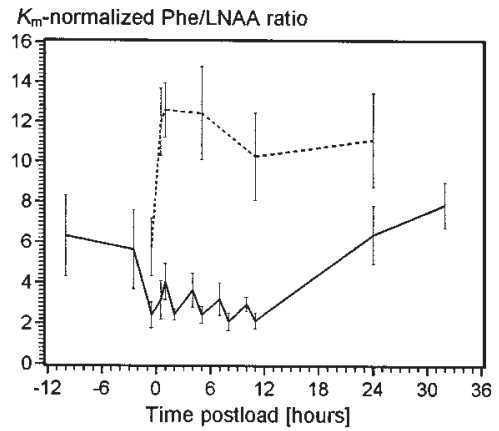

b

Plasma Valine $[\mu \mathrm{mol} / \mathrm{l}]$

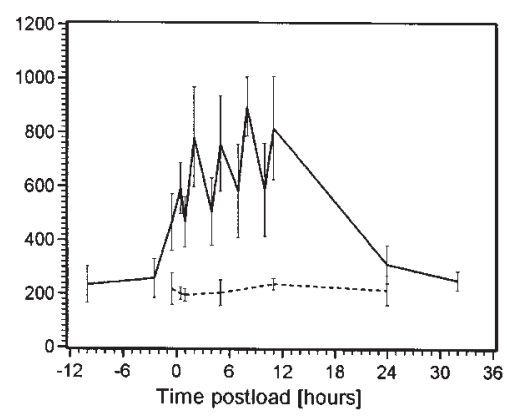

e

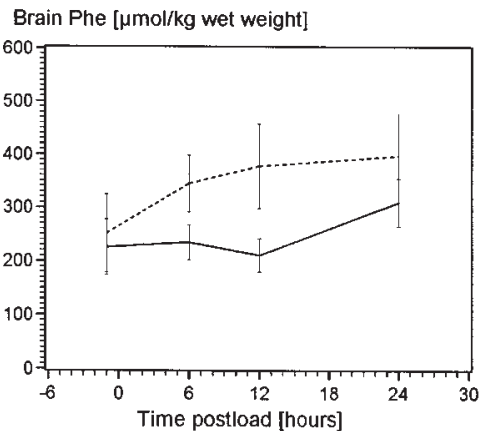

C

Plasma Tryptophan $[\mu \mathrm{mol} / \mathrm{l}]$

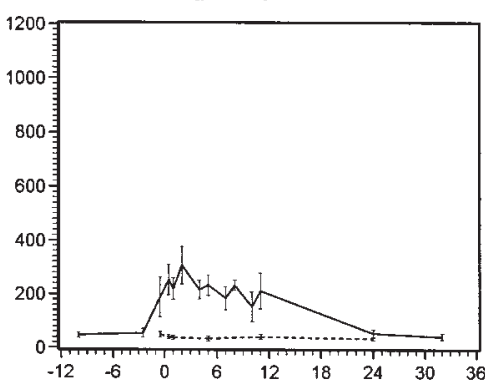

f

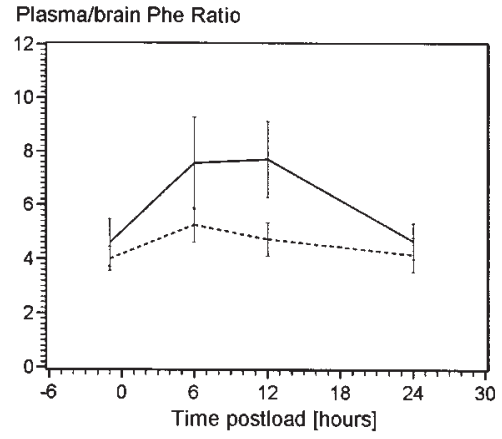

Figure 3

Time course of plasma and brain Phe and examples for LNAAs. (a) Steep increase of plasma Phe levels after an oral dose of L-Phe (time $0 \mathrm{~h}$ ) in the

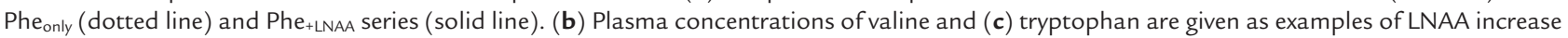

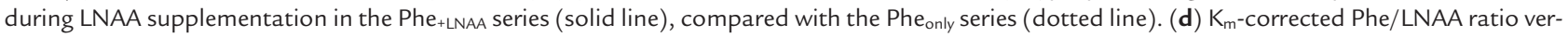

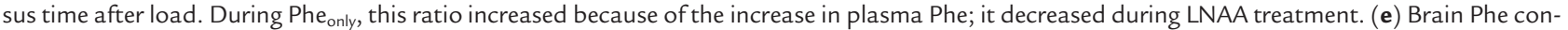

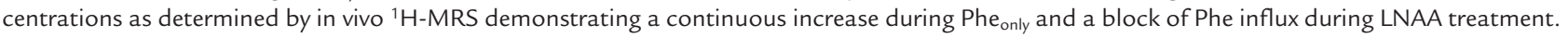
(f) The ratio of plasma/brain Phe increased much more with LNAA treatment than without. All curves represent the average values from all six patients.

logical conditions. Finally, the role of adaptive processes is still quite unclear. Based on results obtained with the double-indicator method, Knudsen et al. (25) speculated that interindividual differences between patients with PKU with regard to $K_{m}$ and $V_{\max }$ could be explained by an upregulation of the number of BBB carriers. The individual time courses of our measured brain versus plasma Phe levels (not shown) appear to confirm a large individual spread in kinetic parameters.

${ }^{1} H$-MRS. As in earlier studies $(8,9,11)$, it was possible to quantitate by ${ }^{1} \mathrm{H}-\mathrm{MRS}$ cerebral Phe concentrations in patients with PKU, thereby confirming the usefulness of ${ }^{1} \mathrm{H}-\mathrm{MRS}$ for the quantitative study of inborn errors of metabolism in general and PKU in particular. The presented results for the steady-state plasma/brain ratio for Phe are in close accordance with our earlier values (average of 4.0 for preload values of the Phe $\mathrm{P}_{\text {only }}$ series versus 4.1 in ref. 11 ).

The preload values of Phe were somewhat different between the two series. It seems quite possible that this small difference is caused by the first dose of LNAAs taken before the baseline measurement. This explanation is supported by the finding that plasma and brain values correlate significantly for the Phe only $_{\text {but not for }}$ the Phe ${ }_{+\mathrm{LNAA}}$ series. It indicates that an increase in plasma LNAA concentration without Phe challenge might be used to lower steady-state brain Phe levels.

With the current setup of ${ }^{1} \mathrm{H}-\mathrm{MRS}$ data acquisition and processing, brain Phe concentrations down to 100 $\mu \mathrm{mol} / \mathrm{kg}$ can be determined reproducibly. This corresponds to a detectable proton density of $500 \mu \mathrm{mol} / \mathrm{kg}$. Given this detection threshold and the spectral pattern of valine (six protons in an upfield doublet), one can estimate that brain valine content remains below 500 $\mu \mathrm{mol} / \mathrm{kg}$ when plasma valine is between 600 and 900 $\mu \mathrm{M}$. Similarly, we did not detect any interfering signals from Trp, Tyr, or histidine in the downfield region during the LNAA series.

With the detection limit achieved, ${ }^{1} \mathrm{H}-\mathrm{MRS}$ is a suitable noninvasive method to characterize the LNAA uptake at the BBB even in healthy subjects. However, it has to be taken into account that cerebral Phe concentrations are determined not only by AA influx but also by efflux and metabolism. These factors, which contribute to cerebral AA concentrations, in principle can be deconvoluted either by dynamically fitting the time course of cerebral Phe elevations or by the use of isotopically labeled precursors. This approach is particularly promising, as alternatives $(25,26)$ are invasive, requiring puncture of the internal jugular vein or application of radioisotopes, and are based on various assumptions.

Möller et al. (27) tried to determine the kinetic characteristics of Phe transport at the BBB by use of steadystate ${ }^{1} \mathrm{H}-\mathrm{MRS}$ measurements and, analogous to glucose transport kinetics (28), application of symmetric Michaelis-Menten kinetics with an arbitrary constant 


\section{Figure 4}

Averaged ${ }^{1} \mathrm{H}-\mathrm{MRS}$ difference spectra (patients minus averaged normal spectra), acquired in vivo before as well as 6,12 , and $24 \mathrm{~h}$ after the oral Phe load. The increase of the Phe peak at 7.37 ppm during the Phe only series (dotted line) contrasts with the unchanged Phe peak 6 and 12 h postload in the Phe + LNAA series (solid line). When LNAA treatment was stopped, brain Phe also increased in this series (measurement at $24 \mathrm{~h}$ ).

Phe consumption rate. This method strongly relies on data obtained from patients with extremely high plasma Phe values and is also susceptible to nonlinearities in Phe quantitation. Their apparent $K_{m}$ and $T_{\max } / V_{\max }$ values do not concur well with the current data if the same simplified model is applied.

Pathophysiology of PKU. The biochemical mechanisms leading to impaired brain development and function in PKU are still the subject of research. Direct effects of elevated Phe concentrations on several enzyme systems, and consequences of a concomitant depletion of other LNAAs in the brain, are thought to be the most important factors for the disturbed brain development in untreated PKU (7). Research has focused on myelin synthesis and turnover, protein synthesis, and amine neurotransmitters. Significant effects were observed with regard to the initiation and further processing of protein synthesis (29). Hyperphenylalaninemia led to a loss of several AAs, especially LNAAs, in the brain of newborn mice, with a concomitant decrease in the incorporation of AAs into protein. Interestingly, the coadministration of LNAAs prevented this effect (30). However, the significance of animal models using experimentally induced hyperphenylalaninemia $(29,30)$ remains questionable because of uncontrolled side effects of the PAH inhibitors used, e.g., $\alpha$-methylphenylalanine.

In addition to their long-term impact on brain structure, high Phe concentrations have acute effects on brain function. However, it is possible that thresholds for acute Phe effects and chronic Phe neurotoxicity in the developing brain are different. It has been discussed that impaired synthesis of serotonin and dopamine could underlie these effects. Krause and colleagues $(1,2)$ found correlations between high plasma Phe levels with decreased performance on neuropsychologic tests of higher integrative function and characteristic changes in the power spectrum of the EEG. As Phe increase led to a concomitant decrease in plasma L-dopa, it was speculated that brain function might be impaired through inhibition of catecholamine synthesis. However, concentrations of neurotransmitters and their metabolites in blood show only a slight relation to the concentration in CSF and even less to that in neuronal cells.

In this study, serial EEG spectral analysis was used to monitor brain activity of patients with PKU during Phe loading. EEG spectral analysis is free of learning effects and is, therefore, an effective and reliable method to evaluate Phe-related impairments of brain function. Because of diurnal variations, comparison of EEG parameters was restricted to parallel measurements between the two series, as well as to preload and $24 \mathrm{~h}$ postload measurements within the series. Our results confirmed the occurrence of specific changes in the frequency spectrum of the EEG background activity with
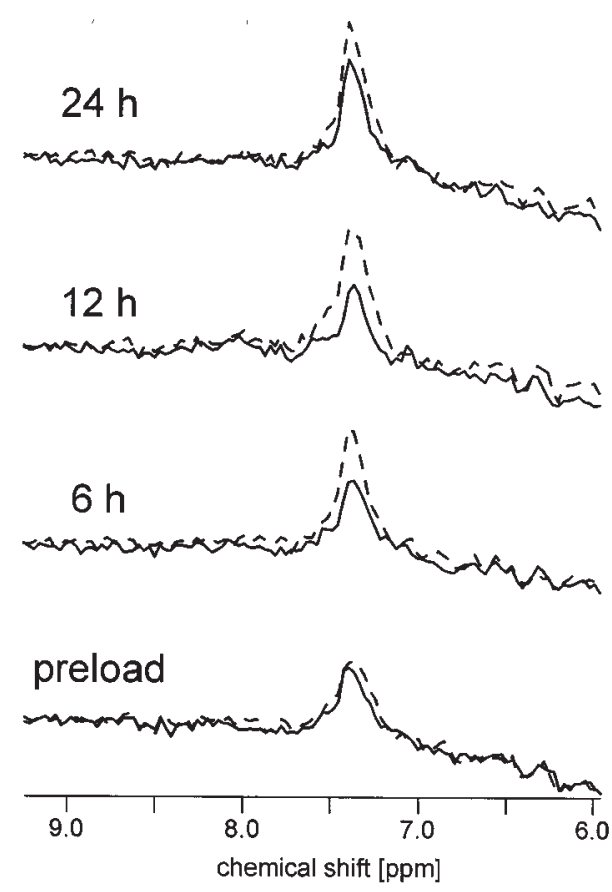

high brain Phe concentrations, which were seen earlier in children (1) and adults (3) with PKU.

Disturbances of the free AA pools of the brain may have further implications for brain function because, in addition to serotonin and dopamine, other AAs (e.g., glutamate, aspartate, glycine) serve as neurotransmitters $(32,33)$. As these AAs use different carrier systems, BBB transport and resulting intracerebral concentrations should not be disturbed during LNAA treatment if plasma levels are not substantially affected. Thus, further LNAA studies should include monitoring of the entire plasma AA profile. Monofunctional explanations, such as the "dopamine depletion hypothesis" (33), disregard the a priori multifunctional character of impairments of brain development and function in PKU. Finally, the causes for acute Phe neurotoxicity, as reflected by the slowing of EEG activity, remain unclear.

Treatment of PKU. Our results have direct implications for the treatment of PKU which was introduced more than 40 years ago (34). In contrast to earlier suggestions that dietary treatment may be terminated after the most vulnerable period of fast brain development and myelin stabilization, there has in recent years been a strong urge toward a strict "diet for life" in some metabolic centers (35). Despite recommendations to continue diet in adult life, most patients relax or stop diet in adolescence (36, 37). Thus, alternative treatment regimes were developed to compensate for the relaxed Phe restriction.

Evidence from in vitro and animal studies, as well as from AA analyses of human CSF, suggests that high Phe concentrations inhibit dopamine and serotonin synthesis. Consequently, high-dose supplementation of the precursor substances Tyr and Trp was tried as an alternative therapeutic approach for adolescent and adult patients off diet (4). However, a substantial benefit of high-dose Tyr could not be confirmed in placebo-controlled studies (38).

The VIL treatment $(150 \mathrm{mg} / \mathrm{kg}$ valine, $150 \mathrm{mg} / \mathrm{kg}$ 
isoleucine, and $200 \mathrm{mg} / \mathrm{kg}$ leucine) was designed to inhibit Phe influx into the brain. Although plasma concentrations of Phe remained unchanged, an $\sim 20 \%$ decrease of Phe concentrations in CSF seemed to confirm the hypothesis. In addition, improvements on a neuropsychologic task were shown for VIL treatment (5, 39). The VIL approach was also used in an animal model of maternal PKU (40). Rats exposed to high phenylalanine levels in utero showed characteristic learning deficits, which could be prevented by VIL treatment. Long-term VIL treatment did not show any side effects. However, as criticized by Hommes (41), CSF Tyr concentrations were lowered further during VIL treatment. It was also noted that the rate at which protein synthesis may be reduced in the PKU brain will depend on the supply of all essential AAs. Thus, the increase of only one (Tyr) or three (VIL) AAs may even accentuate disturbances of neurotransmitter or protein synthesis (42). VIL therapy did not find acceptance in PKU treatment. In the present study, $K_{m}$-corrected Tyr, and Trp ratios improved during LNAA supplementation, even under the condition of steeply increasing plasma Phe levels.

To date, there exists only one report on the use of LNAAs in human PKU. In addition to a Phe-restricted diet, Dotremont et al. (43) used a supplement of $0.8 \mathrm{~g} / \mathrm{kg}$ body weight LNAA mixture. This was well tolerated without adverse effects. Laboratory evaluations were all normal, except for extremely low lysine levels. Also, in our study, a reversible $\sim 30 \%$ decrease of plasma lysine was noticed during LNAA treatment. The causes for this effect are unclear. One possible explanation for this phenomenon could be a stimulation of protein synthesis. However, this result highlights the necessity of careful AA monitoring during supplementation trials. Referring to animal studies that proved lysine deficiency in hyperphenylalaninemic rats, Huether et al. (44) noted that additional lysine supplementation should be considered in PKU treatment. Unfortunately, further data highlighting cerebral Phe concentrations or evaluations of brain function were not reported by Dotrement et al. (43). Before use in the present study, identical LNAA supplementation was studied in three other adult control subjects with normal Phe plasma levels. This trial showed no side effects, and EEG spectra were not influenced by LNAA intake (data not shown).

In standard dietary treatment of PKU, large amounts of free AAs are consumed to compensate for the Pherestricted, and hence, also natural protein-restricted, diet. The present results now raise the question whether such a regular AA mixture may have the previously unexpected effect of lowering brain Phe in addition to replacing natural protein. Ris et al. (45) found negative correlations between verbal intelligence quotient (IQ) and age when formula use was discontinued in adult patients with PKU. This correlation was even stronger than the association of verbal IQ and age when Phe exceeded $1,200 \mu \mathrm{mol} / \mathrm{l}$. Whether patients off diet might profit from the continuing intake of AA mixtures was considered. This speculation is supported by our results. In addition, the profiles of LNAA increase (Figure 3 ) after repeated oral intake elucidate intestinal resorption kinetics and elimination from plasma. These aspects as well as the specific $K_{m}$ values of the AAs used should be considered in further experiments to obtain a more balanced pattern of LNAA concentrations.

Recently, the metabolic effects resulting from large intakes of AA mixtures have been reported (46). The recommended daily amount of $\sim 1.6 / \mathrm{kg}$ body weight AA mixture was given in a single dose to control subjects, leading to a substantial increase of AAs. For example, leucine increased from $\sim 100 \mu \mathrm{mol} / 1$ preload to $\sim 350$ $\mu \mathrm{mol} / \mathrm{l}$. Thus, AA increases were nearly in the range of AA concentrations measured in our study. Side effects of AA intake included an increase of insulin in plasma, leading to significant decreases in blood glucose. Most of these side effects, however, could be prevented by dividing the single dose into three portions per day.

In conclusion, these results show that transport kinetics of carrier systems at the BBB can be quantified noninvasively by ${ }^{1} \mathrm{H}-\mathrm{MRS}$. Evidence is provided that LNAA supplementation blocks Phe influx at the BBB and prevents disturbances of brain electrical activity caused by

\section{Figure 5}

Averaged EEG power spectra from patients with PKU. During the Phe only series (dotted line), a shift of the dominant peak of EEG background activity to the lower-frequency spectrum is demonstrated, which was prevented by LNAA treatment (solid line).

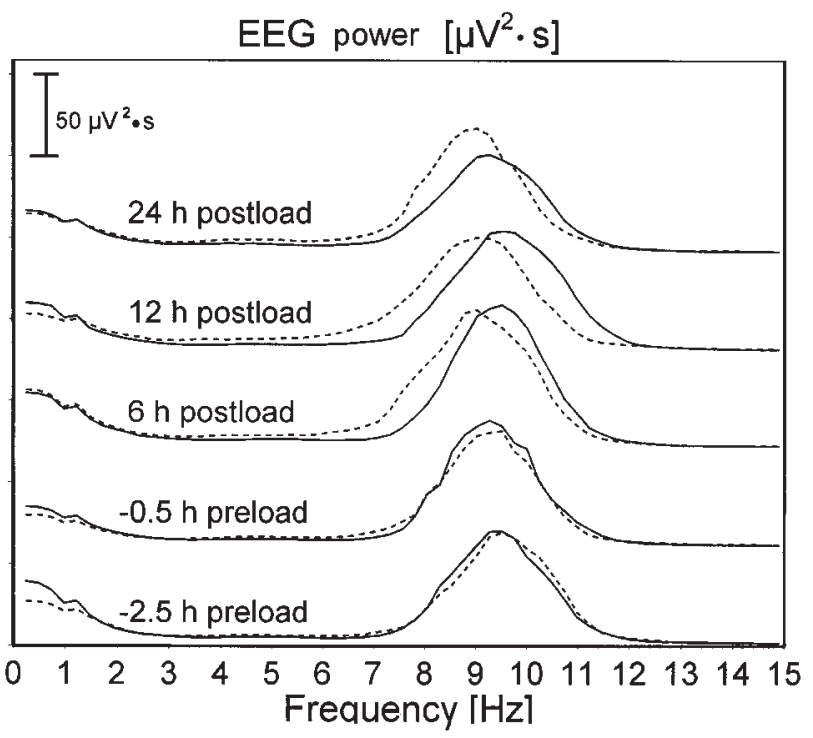


high cerebral Phe concentration in an acute-phase study. Further studies in patients with PKU who are off diet are now warranted to determine whether brain Phe concentration can be lowered during steady state and whether brain function can be improved by long-term continued LNAA supplementation.

\section{Acknowledgments}

Supported by the German Research Foundation (Pi196/3-1), the Medical Faculty University of Heidelberg (69/1996), and the Swiss National Foundation (31-43280.95). The authors thank J. Zschocke (Department of Pediatrics, University of Marburg, Marburg, Germany) for determination of PAH mutations.

1. Krause, W., Epstein, C., Averbook, A., Dembure, P., and Elsas, L. 1986. Phenylalanine alters the mean power frequency of electroencephalograms and plasma L-DOPA in treated patients with phenylketonuria. Pediatr. Res. 20:1112-1116.

2. Krause, W., et al. 1985. Biochemical and neuropsychological effects of elevated plasma phenylalanine in patients with treated phenylketonuria. A model for the study of phenylalanine and brain function in man. $J$. Clin. Invest. 75:40-48.

3. Pietz, J., et al. 1993. EEGs in phenylketonuria. I. Follow-up to adulthood. II. Short-term diet-related changes in EEGs and cognitive function. Dev. Med. Child Neurol. 35:54-64.

4. Lou, H.C. 1985. Large doses of tryptophan and tyrosine as potential therapeutic alternative to dietary phenylalanine restriction in phenylketonuria [letter]. Lancet. 2:150-151.

5. Berry, H.K., Brunner, R.L., Hunt, M.M., and White, P.P. 1990. Valine, isoleucine and leucine. A new treatment for phenylketonuria. Am. J. Dis. Child. 144:539-543.

6. Scriver, C.R., Kaufman, S., Eisensmith, R.C., and Woo, S.L.C. 1995. The hyperphenylalaninemias. In The metabolic basis of inherited disease, volume 1. 7th edition. C.R. Scriver, A.L. Beaudet, W.S. Sly, and D. Valle, editors. McGraw-Hill. New York, NY. 1015-1075.

7. Kaufman, S. 1977. Phenylketonuria: biochemical mechanisms. In Advances in neurochemistry, volume 2. B.W. Agranoff and M.H. Aprison, editors. Plenum Press. New York, NY. 1-132.

8. Novotny, E.J., et al. 1995. In vivo measurement of phenylalanine in human brain by proton nuclear magnetic resonance spectroscopy. Pediatr. Res. 37:244-249.

9. Kreis, R., Pietz, J., Penzien, J., Herschkowitz, N., and Boesch, C. 1995. Identification and quantitation of phenylalanine in the brain of patients with phenylketonuria by means of in vivo ${ }^{1} \mathrm{H}$ magnetic resonance spectroscopy. J. Magn. Reson. B. 107:242-251.

10. Kreis, R. 1997. Quantitative localized ${ }^{1} \mathrm{H}-\mathrm{MR}$ spectroscopy for clinical use. Prog. NMR Spectroscopy. 31:155-195

11. Pietz, J., et al. 1995. The dynamics of brain concentrations of phenylalanine and its clinical significance in patients with phenylketonuria determined by in vivo ${ }^{1} \mathrm{H}$ magnetic resonance spectroscopy. Pediatr. Res. 38:1-7.

12. Guldberg, P., et al. 1998. A European multicenter study of phenylalanine hydroxylase deficiency: classification of 105 mutations and a general system for genotype-based prediction of metabolic phenotype. Am. J. Hum. Genet. 63:71-79.

13. Lutz, P., Schmidt, H., Frey, G., and Bickel, H. 1982. Standardized loading test with protein for the differentiation of phenylketonuria from hyperphenylalaninemia. J. Inherit. Metab. Dis. 5:29-35.

14. Pietz, J., et al. Phenylketonuria: findings at MR imaging and localized in vivo $\mathrm{H}-1 \mathrm{MR}$ spectroscopy of the brain in patients with early treatment. Radiology. 201:413-420.

15. Pardridge, W.M. 1988. Phenylalanine transport at the human bloodbrain barrier. In Dietary phenylalanine and brain function. R.J.Wurtman and E. Ritter-Walker, editors. Birkhäuser. Boston, MA. 56-62.

16. Miller, L., Braun, L.D., Pardridge, W.M., and Oldendorf, W.H. 1985 Kinetic constants for blood-brain barrier amino acid transport in conscious rats. J. Neurochem. 45:1427-1432.

17. Slotboom, J., Boesch, C., and Kreis, R. 1998. Versatile frequency domain fitting using time domain models and prior knowledge. Magn. Reson. Med. 39:899-911.

18. Pardridge, W.M. 1998 Blood-brain barrier carrier-mediated transport and brain metabolism of amino acids. Neurochem. Res. 23:635-644.

19. Pardridge, W.M., and Oldendorf, W.H. 1975. Kinetic analysis of blood-brain barrier transport of amino acids. Biochim. Biophys. Acta. 401:128-136.

20. Smith, Q.R., Momma, S., Aoyagi, M., and Rapoport, S.I. 1987. Kinetics of neutral amino acid transport across the blood-brain barrier. J. New rochem. 49:1651-1658
21. Hargreaves, K.M., and Pardridge, W.M. 1988. Neutral amino acid transport at the human blood-brain barrier. J. Biol. Chem. 263:19392-19397.

22. Herrero, E. Araoon, M.C. Giminez, C and Valdivieso, F. 1983. Inhibition by L-phenylalanine of tryptophan transport by synaptosomal plasma membrane vesicles: implications in the pathogenesis of phenylketonuria. J. Inherit. Metab. Dis. 6:32-35.

23. Knudsen, G.M., Pettigrew, K.D., Patlak, C.S., Hertz, M.M., and Paulson, O.B. 1990. Asymmetrical transport of amino acids across the bloodbrain barrier in humans. J. Cereb. Blood Flow Metab. 10:698-706.

24. Lajtha, A.L., Maker, H.S., and Clarke, D.D. 1981. Metabolism and transport of carbohydrates and amino acids. In Basic neurochemistry. G.J. Siegel, R.W. Albers, B.W. Agranoff, and R. Katzman, editors. 3rd edition. Little, Brown and Co. Boston, MA. 329-352.

25. Knudsen, G.M., Hasselbalch, S., Toft, P.B., and Christensen, E. 1995. Blood-brain barrier transport of amino acids in healthy controls and in patients with phenylketonuria. J. Inherit. Metab. Dis. 18:653-664.

26. Shulkin, B.L., Betz, A.L., Koeppe, R.A., and Agranoff, B.W. 1995. Inhibition of neutral amino acid transport across the human blood-brain barrier by phenylalanine. J. Neurochem. 64:1252-1257.

27. Möller, H.E., et al. 1997. Kinetics of phenylalanine transport at the human blood-brain barrier investigated in vivo. Brain Res. 778:329-337.

28. Gruetter, R., Novotny, E.J., Boulware, S.D., Rothman, D.L., and Shulman, R.G. 1996. ${ }^{1} \mathrm{H}$ NMR studies of glucose transport in the human brain. J. Cereb. Blood Flow Metab. 16:427-438.

29. Hughes, J.V., and Johnson, T.C. 1978. Abnormal amino acid metabolism and brain protein synthesis during neural development. Neurochem. Res. 3:381-399.

30. Binek-Singer, P.A., and Johnson, T.C. 1982. The effects of chronic hyperphenylalaninaemia on mouse brain protein synthesis can be prevented by other amino acids. Biochem. J. 206:407-414

31. Dingledine, R., and McBain, C.J. 1993. Excitatory amino acid neurotransmitters. In Basic neurochemistry. G.J. Siegel, B.W. Agranoff, R.W. Albers, and R. Katzman, editors. 5th edition. Raven Press. New York, NY. 367-387.

32. DeLorey, T.M., and Olsen, R.W. 1993. GABA and glycine. In Basic neurochemistry. G.J. Siegel, B.W. Agranoff, R.W. Albers, and R. Katzman, editors. 5th edition. Raven Press. New York, NY. 389-399.

33. Welsh, M.C., Pennington, B.F., Ozonoff, S., Rouse, B., McCabe E.R. 1990. Neuropsychology of early-treated phenylketonuria: specific executive function deficits. Child Dev. 61:1697-1713.

34. Bickel, H., Gerrard, J., and Hickmans, E.M. 1954. The influence of phenylalanine intake on the chemistry and behaviour of a phenylketonuric child. Acta Paediatr. Scand. 43:64-77.

35. Medical Research Council Working Party on Phenylketonuria. 1993. Recommendations on the dietary management of phenylketonuria. Arch. Dis. Child. 68:426-427.

36. Weglage, J., Fünders, B., Wilken, B., van Teeffelen-Heithoff, A., Ullrich, K. 1993. Treatment of phenylketonuria: wish and reality. Monatsschr. Kinderheilkd 141:670-674.

37. Pietz, J., et al. 1997. Psychiatric disorders in adult patients with earlytreated phenylketonuria. Pediatrics. 99:34-350

38. Pietz, J., et al. 1995. Effect of high-dose tyrosine supplementation in adults with phenylketonuria. J. Pediatr. 127:1-8.

39. Berry, H.K., Bofinger, M.K., Hunt, M.M., Phillips, P.J. and Guilfoile, M.B. 1982. Reduction of cerebrospinal fluid phenylalanine after oral administration of valine, isoleucine, and leucine. Pediatr. Res. 16:751-755.

40. Vorhees, C.V., and Berry, H.K. 1989. Branched chain amino acids improve complex maze learning in rat offspring prenatally exposed to hyperphenylalaninemia: implications for maternal phenylketonuria. Pediatr. Res. 25:568-572.

41. Hommes, F.A. 1989. The role of the blood-brain barrier in the aetiology of permanent brain dysfunction in hyperphenylalaninaemia. J. Inherit. Metab. Dis. 12:41-46.

42. Pratt, O.E. 1982. Transport inhibition in the pathology of phenylketonuria and other inherited metabolic diseases. J. Inherit. Metab. Dis. 5(Suppl. 2):75-81

43. Dotremont, H., Francois, B., Diels, M., and Gillis, P. 1995. Nutritional value of essential amino acids in the treatment of adults with phenylketonuria. J. Inherit. Metab. Dis. 18:127-130.

44. Huether, G., Kaus, R., and Neuhoff, V. 1985. Amino acid depletion in the blood and brain tissue of hyperphenylalaninemic rats is abolished by the administration of additional lysine: a contribution to the understanding of the metabolic defects in phenylketonuria. Biochem. Med. 33:334-341.

45. Ris, M.D., Williams, S.E., Hunt, M.M., Berry, H.K., and Leslie, N. 1994. Early-treated phenylketonuria: adult neuropsychologic outcome. J. Pediatr. 124:388-392.

46. Mönch, E., Herrmann, M.-E., Brösicke, H., Schöffer, A., and Keller, M. 1996. Utilisation of amino acid mixtures in adolescents with phenylketonuria. Eur. J. Pediatr. 155(Suppl. 1):S115-S120. 